\title{
REDUCING POLLUTION LEVELS GENERATED BY SHORT SEA SHIPPING. USE OF BAYESIAN NETWORKS TO ANALYSE THE UTILIZATION OF LIQUEFIED NATURAL GAS AS AN ALTERNATIVE FUEL
}

\author{
Beatriz Molina Serrano, Nicoleta González Cancelas \\ Polythecnic University of Madrid, Civil Engineering Department Transports \\ Avd. Profesor Aranguren s/n, Madrid 28040, Spain \\ tel.: +34 9133664 28, fax: +3491336 6428 \\ e-mail: beatriz.molinas@alumnos.upm.es,nicoleta.gcancelas@upm.es
}

Francisco Soler Flores

UNIR. Education Faculty

c/Almirante Francisco Moreno 3, 3E 28040 Madrid

tel.: +34913366428,fax: +34913366428

e-mail:francisco.soler@unir.net

\begin{abstract}
Pollution adjacent to the continent's shores has increased in the last decades, so it has been necessary to establish an energy policy to improve environmental conditions. One of the proposed solution was the search of alternative fuels to the commonly used in Short Sea Shipping to reduce pollution levels in Europe. Studies and researches show that liquefied natural gas could meet the European Union environmental requirements. Even environmental benefits are important; currently there is not significant number of vessels using it as fuel. Moreover, main target of this article is exposing result of a research in which a methodology to establish the most relevant variables in the decision to implement liquefied natural gas in Short Sea Shipping has been development using data mining. A Bayesian network was constructed because this kind of network allows to get graphically the relationships between variables and to determine posteriori values that quantify their contributions to decision-making. Bayesian model has been done using data from some European countries (European Union, Norway and Iceland) and database was generated by 35 variables classified in 5 categories. Main obtained conclusion in this analysis is that variables of transport and international trade and economy and finance are the most relevant in the decision-making process when implementing liquefied natural gas. Even more, it can be stablish that capacity of liquefied natural gas regasification terminals under construction and modal distribution of water cargo transportation continental as the most decisive variables because they are the root nodes in the obtained network.
\end{abstract}

Keywords: Bayesian networks, graph theory, artificial networks, European Union, Short Sea Shipping, liquefied natural gas

\section{Introduction}

Economic globalization generated in the 1990s an international trade growth, which increased congestion in the main road corridors and road traffic externalities, such as pollution and accident rates. In particular case of Europe, entrance of new countries into the European Union promoted congestion increasing too. Thus, congestion increasing even threatened European economic competitiveness [8], so, it was necessary to carry out a continental strategy.

European global strategy tried to reduce road traffic levels; so, it proposed to carry cargo by sea as far as possible. Therefore, maritime transport becomes a complement to the transport of goods by road. Main targets of this strategy were reducing the damage generated to the environment, reducing accidents and saturation of infrastructure and increasing energy 
efficiency [7].

Promoting short sea shipping was expected to optimize modes of transport, to decongest roads and to decrease $\mathrm{CO}_{2}$ and $\mathrm{SO}_{x}$ emissions. Moreover, it was hoped to guarantee the connection between the sea, the waterways, and the railroad, through intermodality [14]. Studies, such as RECORDIT [24] and REALISE [22, 23], demonstrated that intermodal transport reduces total internal and external costs, being the best economic alternative comparing to unimodal transport [16].

For this reason, the European Commission promotes Short Sea Shipping as an alternative to unimodal transport, defining it as the good/passengers transport between the mainland ports or between the European Union ports and other ones located in its influence area (Mediterranean Sea, Black Sea and Baltic Sea,).

Despite maritime transport, have the lowest environmental impacts among the rest of transport modes, large quantities of harmful substances, gases and particles are released from the ships into the air [18]. Therefore, this strategy increased pollution adjacent to the continent's shores. It was caused by the fuel used in feeder-class vessels, which produces greenhouse gas emissions and high levels of particulate emissions of Sulphur oxide [20]. Consequently, it was necessary to establish an energy policy proposing solutions on supply the growth effects in European environment [9]. One of the proposed solution was the search of alternative fuels to the commonly used in Short Sea Shipping to reduce pollution levels.

There are many literature about possible solutions, Short Sea Shipping impacts and policy recommendations on climate change, but there is no related to regulation in the maritime transport sector financial impact [3]. For example, Psaraftis and Kontovas [21] affirm some solutions to reduce greenhouse gases is to create low consumption engines, to find optimum propulsion, to use alternative fuels or to purifiers in the exhaust.

Relating to alternative fuels, studies and researches show that the only kind of fuels that could meet the European Union environmental requirements, which are the three ones: heavy fuel oil, marine gas oil, and liquefied natural gas.

The last one can be considered as an alternative in a short term, because its main advantages are the followings ones by [6]:

- It has slightly lower $\mathrm{CO} 2$ emissions than the traditional fuel. It produces less greenhouse gas emissions than generated by diesel fuels and it is only $1 \%$ less efficient than they are.

- It has no emission of Sulphide Dioxide and Nitrogen Oxide

Even environmental benefits are important; currently there is not significant number of vessels using it. The main reasons is that its implementation requires significant investment because it is necessary to bring gas to intermediate terminals or storage tanks and because its strict environmental regulation modifies traditional maritime governance forms [1, 12].

However, considering the rest of fuels to use in Short Sea Shipping, liquefied natural gas is considered as the best alternative due to there are no geographical limits in infrastructure availability at current market-adjusted price; due to oil dependence reduction and due to environmental impact reduction [5].

So, the main target of this article and its principal contribution is to show result of a research in which we have develop a methodology to establish the most relevant variables in the decision to implement liquefied natural gas in Short Sea Shipping, through Bayesian networks. Acedo and Almazán [1] consider that in a short term, liquefied natural gas will comply European transport policy guidelines and regulations as a fuel. Then liquefied natural gas will allow sources of energy supply diversification, cost saving, positive environmental impact generation, and Short Sea Shipping routes strengthening, even creating new ones.

\section{Materials and methods}

The methodological proposal is based in a Bayesian network construction, because this kind of 
networks allows determining the relationship between the variables that define the use of liquefied natural gas in short sea shipping in the European Union.

A Bayesian network is a kind of directed graphical model in which arc directionality is taken account. These networks allow to get in graphical form relationships between variables and to determine a posteriori values that quantify their contributions [4].

Bayesian networks represent, in a compact way, a multivariate probability distribution. Therefore, each network node is associated with a probability distribution conditioned to the parents of that node. For this reason, joint distribution multiplies the conditioned distributions associated with the network nodes.

Thus, a Bayesian structure could be determined as follow:

1) Each variable is associated to a node and it is called $\mathrm{Xj}$. It is necessary indicate other nodes in which $\mathrm{Xj}$ is a directed cause. These set of nodes, which is "node $(\mathrm{Xj})$ cause is called $\pi \mathrm{Xj}$ and they are considered "Xj parents".

2) Arcs joint parents with sons. Arcs begin in parents and finish in sons.

3) A $P(X j \mid \pi X j)$ matrix is assigned to each node $X j$. This matrix estimates conditional probability to a specific event, so $\mathrm{Xj}=\mathrm{xj}$ if a $\pi \mathrm{Xj}$ combination valour is given. Bayesian networks allow defining models and using them to make diagnosis reasoning and predicting reasoning, because they can obtain more probable causes of a set of symptom and can obtain probability of a certain symptom supposing that a known cause exits too.

Equation (1) represents a network with $n$ variables $(j=n)$.

$$
p\left(x_{1}, \ldots, x_{n}\right)=\prod_{i=1}^{n} p\left(x_{1} \mid x_{p a(i)}\right) \text {. }
$$

The probabilistic networks allow probabilistic modelling process automation by using graphs expressivity. Resulted models have relationship between variables, and their probability (relationship quantification). It allows to realize model automatic learning and in last term, inference. Basic knowledge of these systems is an estimation of the joint probability function of all considered variables. However, conditioned probabilities calculation is done in reasoning module.

Rodríguez and Dolado [25] assert that engineering knowledge in Bayesian Networks is the process of construction, validation, and use of Bayesian networks. This is done by means of the network structure or graph definition and network parameters definition. Therefore, it is necessary to follow Fig. 1 steps:

The use of Bayesian networks for the graphical representation of the relations between variables brings with it a great number of advantages, such as facilitation of causal relations understanding of the using the graph [19]. Some of these advantages are the following ones:

- Bayesian networks allow simultaneous representation of quantitative dimension (probability tables) and qualitative (graph) of an specific problem,

- they can be constructed with incomplete data [13, 19],

- it is possible to perform a sensitivity analysis [15, 25] and can make predictions with incomplete information, among others using a Bayesian two-way inference [19, 25],

However, this kind of networks presents some construction difficulties, such as the computational cost to explore a previous unknown network, and such as initial parameters quality and scope, because they can distort he results [17].

Methodology used in the research consists on Fig. 2 three steps:

\subsection{Work scenario definition}

The first step consists on define work scenario and obtain data to conform database of research. It is necessary to consult several sources and review previous bibliography.

Firstly, it is necessary make a geographical delimitation. In the research, geographical delimitation is Europe zone, because data belong to European Union members (28 countries), 
Norway and Iceland.

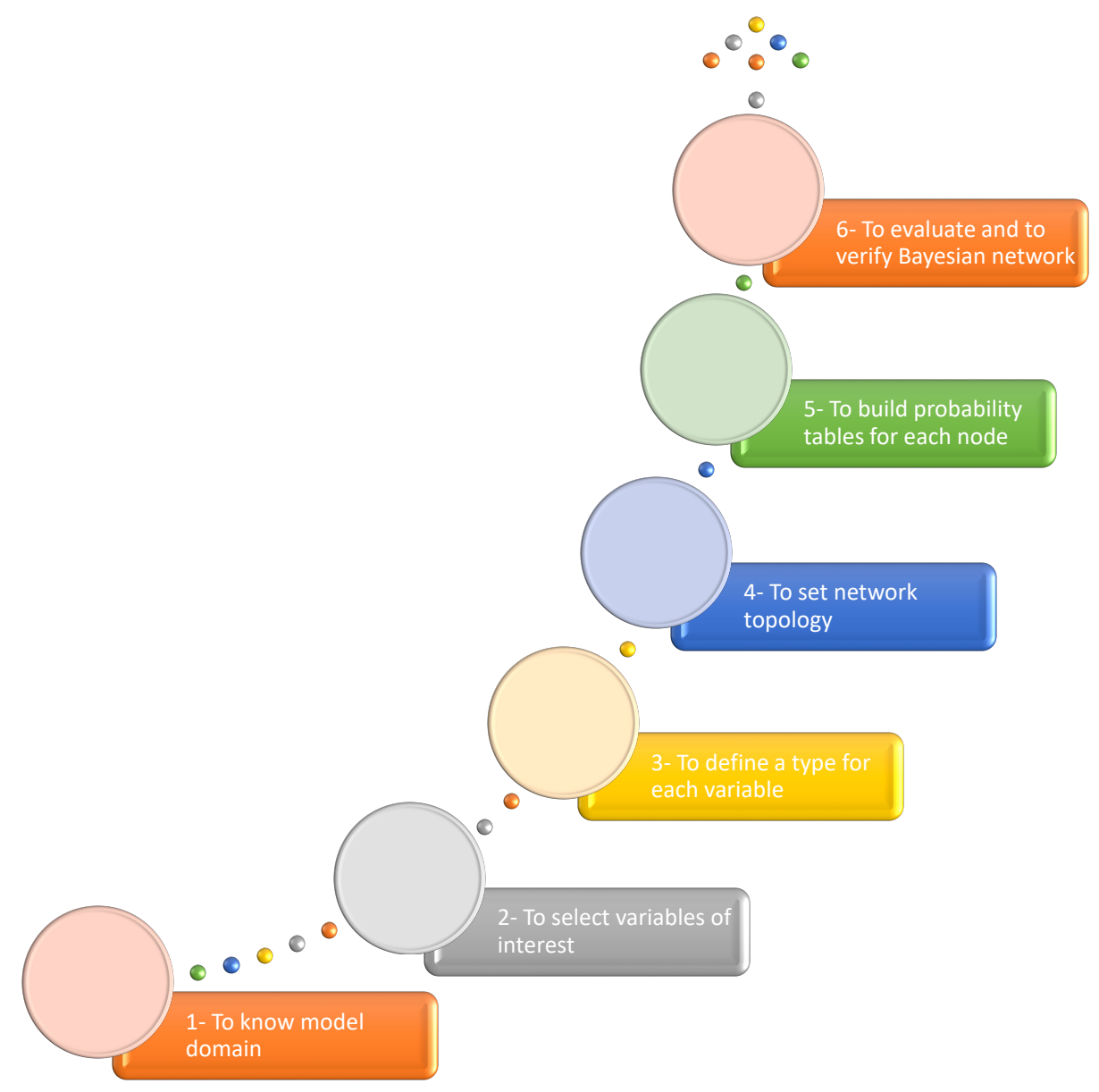

Fig. 1. Steps to construct a Bayesian network
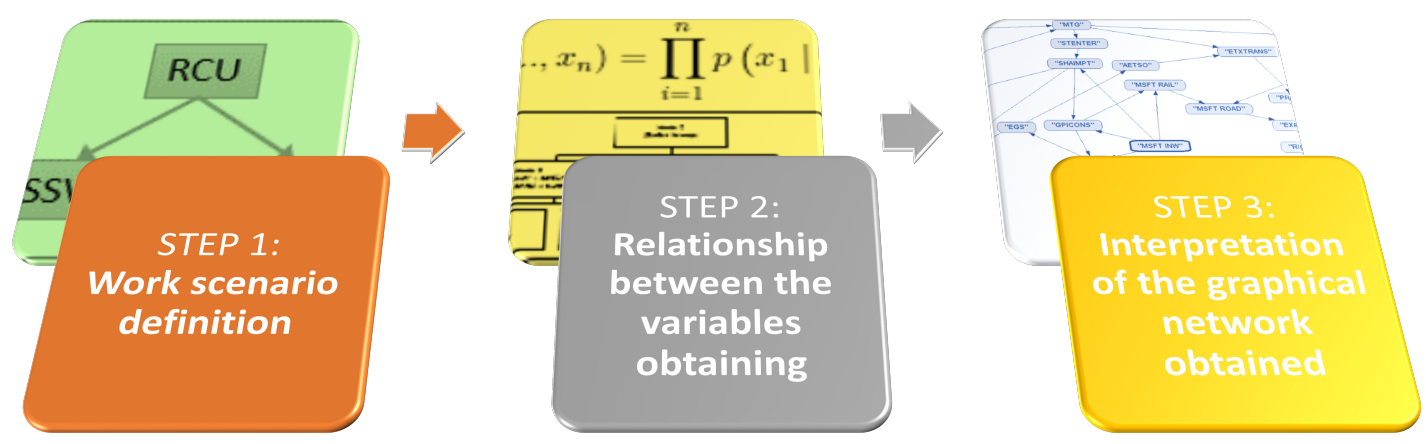

Fig. 2. Methodology scheme

Following, it is necessary to determinate and obtains variables to be considered. Then, they have to be classified into groups in order to observing relationships between the variables and to facilitate understanding in the posterior network analysis.

In research, variables were selected considering their relationship with liquefied natural gas and Short Sea Shipping and even some more were included even they have no apparent relationship with the topics to analyse. Consulted sources were Eurostat, European Gas Infrastructure Association (GIE) and the European LNG terminal infrastructure 2015: Status and Outlook document.

Selected variables were grouped into the 5 groups shown in Fig. 3. Group separation was made 
according to variable nature.

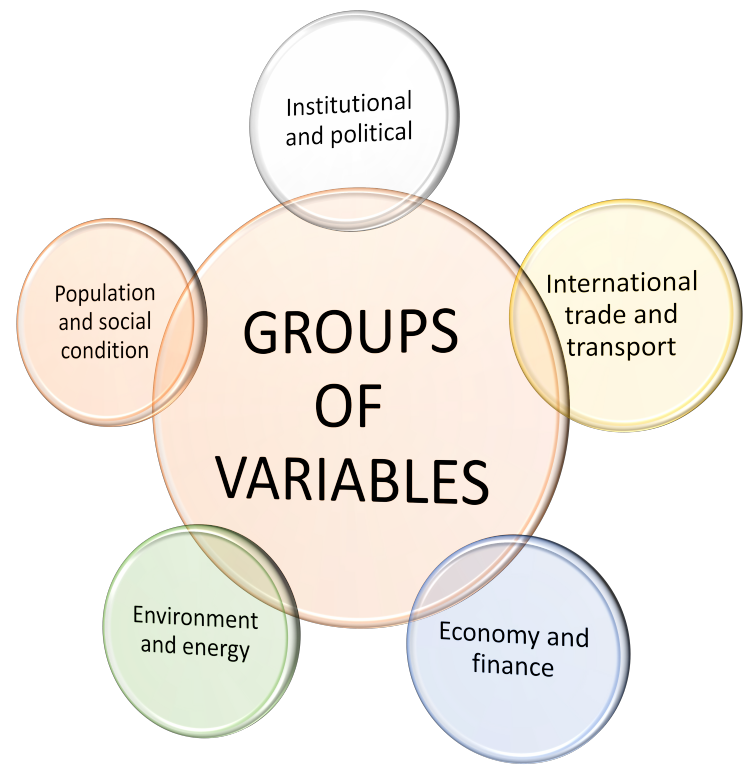

Fig. 3. Variable categories

The set of 35 variables that conform research database are included in Tab. 1 . There, variables are classified in groups defined before.

\subsection{Relationship between the variables obtaining}

The relationship between selected variables is obtained using a directed graph analysis, because a Bayesian network is an acyclic directed graph where each node is referred to a random variable and variable relationships are encoded in the graph structure according to separation criterion.

After selecting the study variables, it is necessary variable discretization for model construction. Discrete or nominal variables are usually use in Bayesian networks, so if they are not discrete ones, it is necessary to discretize them before model construction. However, use of continuous variables is possible working with Bayesian networks, but their use is limited to Gaussian variables and linear relationships.

Discretization consists on dividing range of continuous variables into a finite number of exhaustive and exclusive intervals. Tools generally need discretized attributes when using Bayesian networks. To discretize attributes it is necessary to select the number of intervals, so intervals are divided taking into account the number of instances in each interval or even using the same distance.

In the research, it was only considered discrete variables, so it was necessary to discretize continuous ones. This task was performed according to expert criteria for the strata selection and allowed transforming continuous attributes into intervals. Domain expert decided the number of intervals, rejected or corrected instances with outliers, and so on.

There are two discretization types, unsupervised and supervised type, but discretization type is a developed software option. In particular, software used in the research was Elvira. It was selected because it has a format for models coding, a coded model reader-interpreter, a network construction interface, and decision-making algorithms.

When pre-processed data is finished, learning process begins (data mining process). In Bayesian networks, this step consists on learning network structure and generating probability tables for each node. In most cases, in this step domain experts will also be necessary to define network structure, to complete network or only a part of it, to decide arc directions (cause-effect 
Tab. 1. Selected variables in research

\begin{tabular}{|c|c|c|}
\hline \multicolumn{3}{|c|}{ Transportation and international trade } \\
\hline Variable & Indicator & Unit \\
\hline MTG & Maritime Transport & Thousands of tones \\
\hline MSFT RAIL & Modal distribution of freight transport by rail & Percentage \\
\hline MSFT ROAD & Modal distribution of freight transport by road & Percentage \\
\hline MSFT INW & $\begin{array}{l}\text { Modal distribution of freight transport } \\
\text { by continental waters }\end{array}$ & Percentage \\
\hline SSS VTEU & TEUs in short sea shipping & 1000 TEU's \\
\hline \multicolumn{3}{|c|}{ Economy and Finance } \\
\hline Variable & Indicator & Unit \\
\hline GDP & Gross domestic product & Thousands of euros \\
\hline EGS & Exports from member states to third countries & Thousands of euros \\
\hline IGS & Imports from third countries to member states & Thousands of euros \\
\hline GOVDEF & Debt, Public surplus & $\%$ GDP \\
\hline PROIND & Production in industry & Index, $2010=100 \%$ \\
\hline PROCON & Production in construction & Index, $2010=100 \%$ \\
\hline SHAIMPT & Participation in imports by EU member & $\%(E U=100 \%)$ \\
\hline SHAEXPO & Participation in exports by EU member & $\%(\mathrm{EU}=100 \%)$ \\
\hline \multicolumn{3}{|c|}{ Environmental and Energy } \\
\hline Variable & Indicator & Unit \\
\hline AETSO & SOx emissions from transport and communication & Tones \\
\hline GHGTR & Emissions of greenhouse gases from transport & Thousands of tones \\
\hline ETXTRANS & Environmental taxes on transportation & Thousands of euros \\
\hline GENWAS & Total generation of waste & Tones \\
\hline GPICONS & Prices of natural gas for industrial use & Euro/Kilowatt-hour \\
\hline WELEC & $\begin{array}{l}\text { Waste electrical and electronic equipment } \\
\text { produced by households }\end{array}$ & Kilograms per capita \\
\hline REPRO & Productivity of resources & Euro/Kilogram \\
\hline GHGAGR & Emissions of greenhouse gases from agriculture & Thousands of tones \\
\hline \multicolumn{3}{|c|}{ Institutional and Politic } \\
\hline Variable & Indicator & Unit \\
\hline SECA & Sulphur Emission Control Areas & Number \\
\hline SFRONT & Geographical location of the coasts & Number \\
\hline $\mathrm{RCO}$ & $\begin{array}{l}\text { Capacity of liquefied natural gas regasification } \\
\text { terminals in operation }\end{array}$ & billons $\mathrm{m}^{3}$ per year \\
\hline RCU & $\begin{array}{l}\text { Capacity of liquefied natural gas regasification } \\
\text { terminals under construction }\end{array}$ & billons $\mathrm{m}^{3}$ per year \\
\hline $\mathrm{RCP}$ & $\begin{array}{l}\text { Capacity of liquefied natural gas regasification } \\
\text { terminals in plans }\end{array}$ & billons $\mathrm{m}^{3}$ per year \\
\hline FDG & Form of government & Number \\
\hline EPG & Models of port management in Europe & Number \\
\hline \multicolumn{3}{|c|}{ Population and social condition } \\
\hline Variable & Indicator & Unit \\
\hline RDEXPN & Total expenditure on research and development & Euro/habitant \\
\hline POBL & Population & Habitants \\
\hline LIFEEXP & Life expectancy & Age \\
\hline RISKPOV & Population at risk of poverty or social exclusion & Population percentage \\
\hline UNER & Unemployment rate & $\begin{array}{l}\text { Active population } \\
\text { percentage }\end{array}$ \\
\hline STENTER & Students enrolled in tertiary education & Population \\
\hline EXPSPBE & Expenditure on social protection & Euro/habitant \\
\hline
\end{tabular}


relationships) and to define root/leaf nodes and/or parameters as thresholds, algorithms. Once the network is obtained, it may need to be edited to add, delete, or reverse defined arcs.

Finalized variable discretization, structural learning starts. It consists on finding dependence relationships between the variables, which allows determining Bayesian network topology. Depending on structure type, it is possible to apply different methods of this learning: learning poly-trees, learning trees, multiconnected networks, learning methods based on measures and search and methods based on dependency relationships.

In research, K2 algorithm has been used to construct Bayesian network. This algorithm is based on measure optimization, so it is very useful in planning. Its work begins in an initial network and it is modifying during the process. Obtained result is a new network with better measure.

Specifically, K2 measure [10] for a G network and a D database is as follows (2):

where:

$$
f(G: D)=\log P(G)+\sum_{i=1}^{n}\left[\sum_{k=1}^{s j}\left[\frac{\log \left(\Gamma\left(\eta_{i k}\right)\right)}{\Gamma\left(\eta N_{I K}+\eta_{I K}\right)}+\sum_{j=1}^{r i} \frac{\log \left(\Gamma\left(\eta N_{i j k}+\eta_{i j k}\right)\right)}{\Gamma\left(\eta_{i j k}\right)}\right]\right],
$$

$\mathrm{N}_{\mathrm{ikj}}$ - the configurations frequency that is found in D database of the variables Xi

$\mathrm{n}$ - the number of variables, taking its $\mathrm{j}$ value and its parents in $\mathrm{G}$ taking its $\mathrm{k}$ configuration, where if it is the number of possible configurations of set of parents and

ri - the number of possible values for variable xi.

Bayesian networks have not long been incorporated into port planning, but based on some author ideas $[2,11]$; probability factorizations represented by Bayesian networks can be used to perform classifications. Bayesian networks allow considering special variable existence to be classified, and even allow predicting it from the rest of variables. Therefore, network structure obtained can be useful to predict variable values by assigning values to the predictor ones and the subsequent evidence propagation included in the network. That is, by calculating a posteriori probability of special variable associated node, it is possible to obtain values of the rest of variables.

When the system contains a small number of variables, Bayesian network construction can be constructed in a manual way. However, actually, it is necessary to automate the network construction process because most databases contain a large number of variables that make manual construction difficult [32].

Then, according to this methodology, ta Bayesian network is constructed from the database formed by 35 variables classified in 5 categories (Fig. 4).

\subsection{Interpretation of the graphical network obtained}

Finally, it is necessary to analyse obtained network aim to define relationships between variables and to identify those, which are taken down from the network because they have no relationship with the rest of considered variables.

From this analysis, it is possible to obtain useful conclusion about consequences of using liquefied natural gas in short sea shipping in European countries.

\section{Results}

Figure 4 shows that FDG (form of government) is not related to the rest of variables of the network, so it is not cause or effect of any of them.

On the other hand, it is also possible to see that RCU (capacity of liquefied natural gas regasification terminals under construction), from international trade and transport group, and MSFT INW (modal distribution of cargo transport by inland waters), from institutional and political, are the two root nodes of the network. They are the only variables that are parents and not children of other variables involved in the network. Both variables are considered as decisive ones 
and they appear in the network as a "node" variable from which arcs come out. So, divergent connections are generated in both of them.

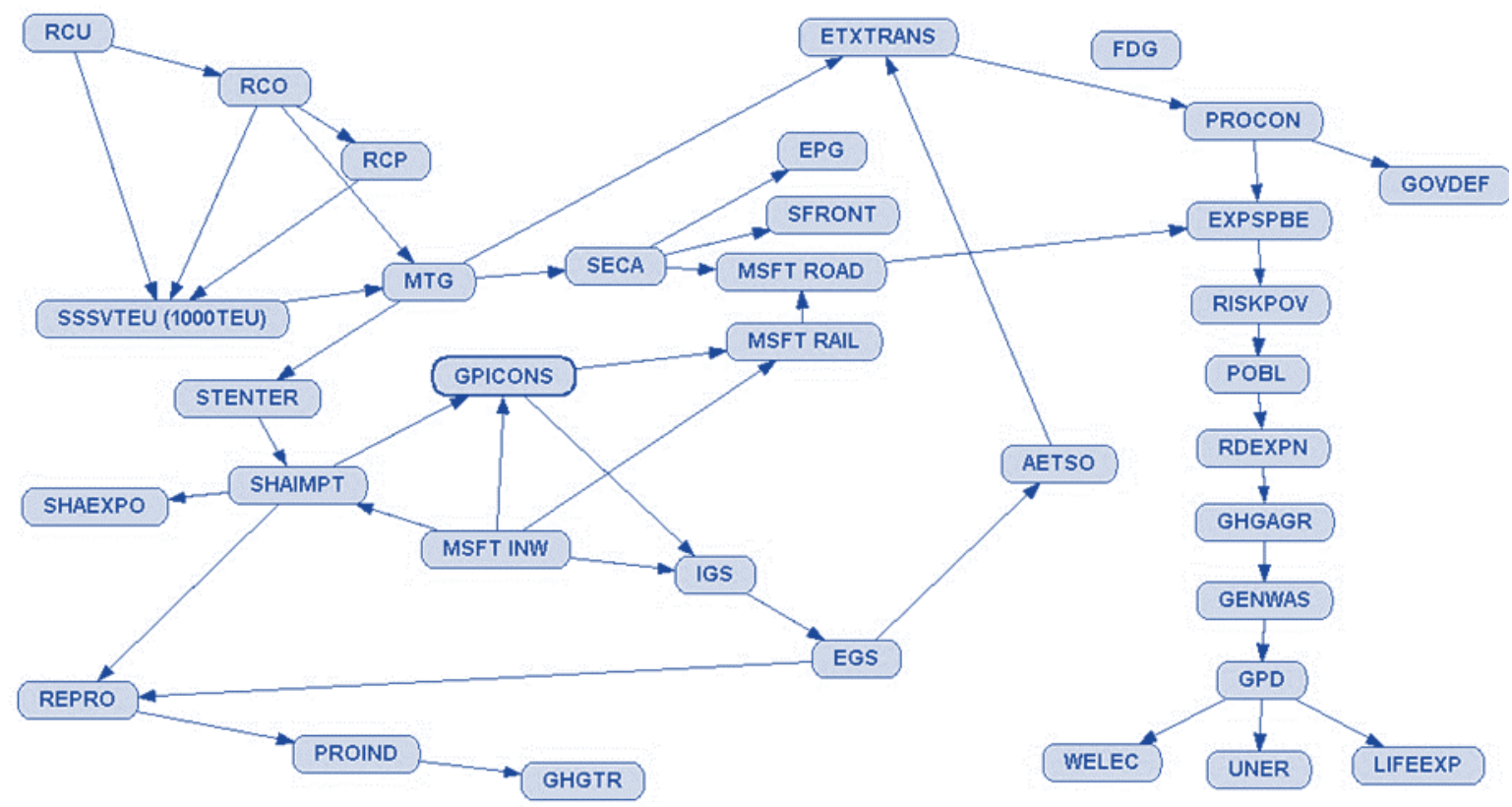

Fig. 4. Obtained Bayesian network

RCU (capacity of liquefied natural gas regasification terminals under construction) has a parent node that projects all its arcs to 2 children, as it can be seen in Fig. 5. This means that RCO (capacity of liquefied natural gas regasification terminals in operation) and SSSVTEU (TEUs in short sea shipping) are a consequence of RCU (capacity of liquefied natural gas regasification terminals under construction).

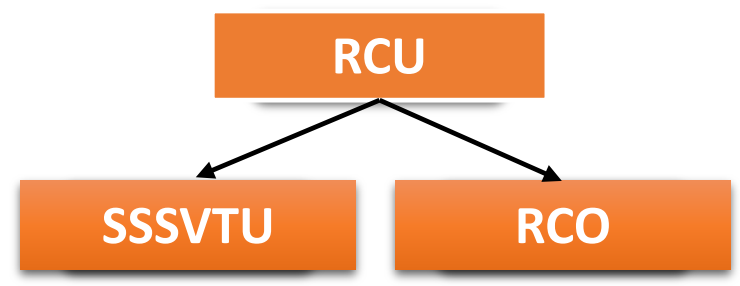

Fig. 5. RCU divergent connections

The second root node, MSFT INW (modal distribution of cargo transport by inland waters) has 4 sons, because 4 arcs start on it and diverge towards their 4 children. Consequently, IGS (imports from member states to third countries), GPICONS (prices of natural gas for industrial use), MSFT RAIL (modal distribution of freight by rail), and SHAIMPT (participation in imports by EU member) are a consequence of it, as Fig. 6 shows.

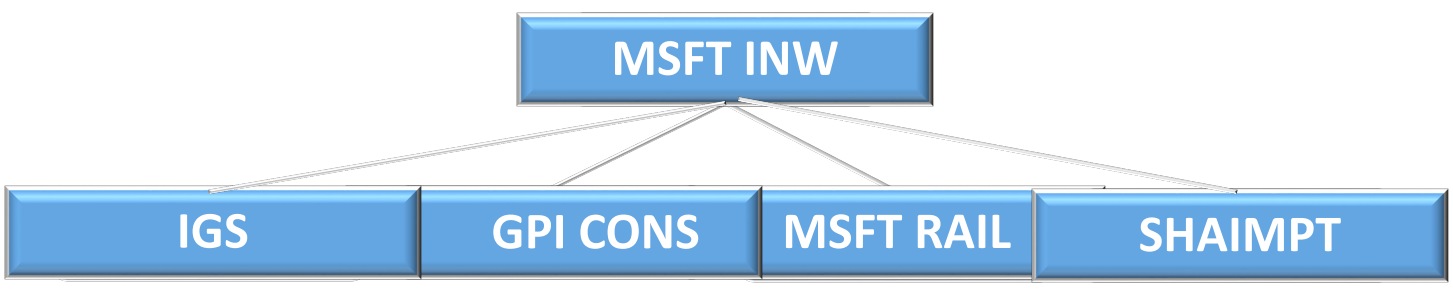

Fig. 6. MSFT INW divergent connections 
However, there is not only divergent relationship in the network. Analysing it, convergent relationships can be obtained. For example, there is this kind of relationship considering SHAIMPT (participation in imports by EU member). This variable has two parents, as Fig. 7 shows. Their parents are STENTER (students enrolled in tertiary education) and MSFT INW (modal distribution of cargo transport by inland waters) because they converge on it. In other words, there are two alternative causes of SHAIMPT. In this kind of connections, parents are independent of each other, but if one of them has the evidence about the son, parents become dependent.

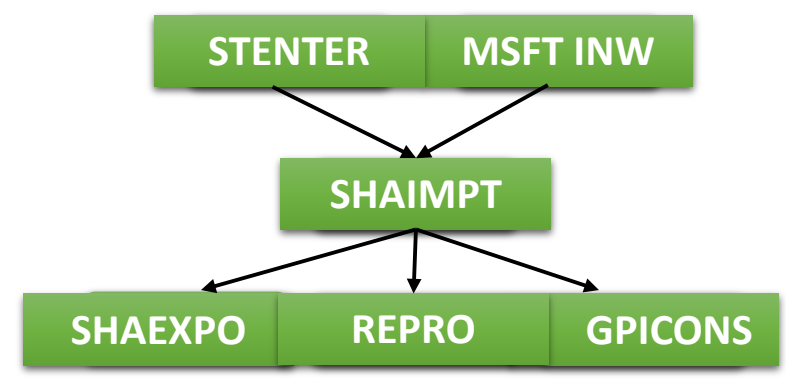

Fig. 7. SHAIMPT connections

Continuing SHAIMPT analysis, it can be concluded that it is a decision variable, because it appears in the network as a variable "node" with 3 divergent. Therefore, SHAEXPO (participation in exports by EU member), REPRO (resource productivity), and GPICONS (industrial natural gas prices) are an indirect effect of (students enrolled in tertiary education) and MSFT INW (modal distribution of cargo transport by inland waters).

Furthermore, another decision variable of the network is included in Fig. 8. There, it can be seen that SSSVTEU (TEU's in Short Sea Shipping) has three arcs, which converge on it. Therefore, RCP (capacity of liquefied natural gas regasification terminals in plans), RCO (capacity of liquefied natural gas Regasification Terminals in Operation), and RCU (capacity of liquefied natural gas regasification terminals under construction) are its parents. Indicate that these parents belong to institutional and political group.

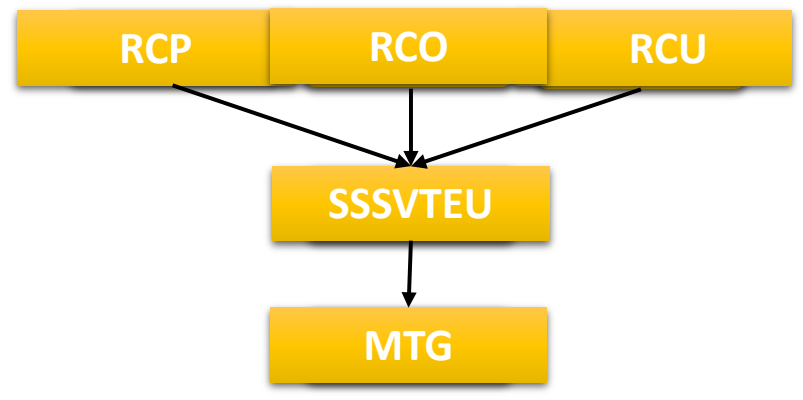

Fig. 8. SSSVTEU connections

Additionally, Fig. 8 shows that SSSVTEU (TEU's in Short Sea Shipping) diverges towards MTG (maritime transport), so it is consequence of SSSVTEU. Consequently, MTG is an indirect consequence of RCU (capacity of liquefied natural gas regasification terminals under construction) because it is related to the rest of network.

Moreover, network shows that SECA (sulphur emission control areas) is another variable that is considered as decisive. It has a parent, MTG (maritime transport), which is son of SSSVTEU (TEU's in short sea shipping). Therefore, SECA depends on MTG and at the same time, MTG depends on SSSVTEU. Furthermore, SECA differs in 3 variables: MSFT ROAD (modal 
distribution of road freight), SFRONT (geographical location of the coasts) and EPG (port management models in Europe). All of them depend in an indirect way of RCU (capacity of liquefied natural gas regasification terminals under construction), as shown in Fig. 5.

Likewise, SECA depends on MTG; maritime transport depends on variables related to the capacity of the European gas infrastructure that is in operation and under construction, as well as the TEU'S in the Short Sea Shipping (SSSVTEU).

On the other hand, the network shows another kind of connection called serial connections. In Fig. 9, it can be seen that EXPSPBE (social protection expenditure) depends on MSFT ROAD (modal distribution of road freight transport) and PROCON (production in construction) and latter depends on ETXTRANS (Environmental taxes on Transportation) and so on. In term of causeeffect, it can be said that ETEXTRANS is cause of PROCON and PROCON is cause of EXPSPBE, so, ETEXTRANS is an indirect cause of EXPSPBE. In other words, in this kind of connections if dependence between the variables is given, information about ETXTRANS could modify certainty about EXPSPBE state. Furthermore, if something about EXPSPBE state is known, belief about ETXTRANS state will be altered (Fig. 9).

Analogously, RISKPOV (population at risk of poverty or social exclusion) depends on EXPSPBE (expenditure on social protection) and POBL (population), and it depends on RISKPOV and so on until the end of the series (Fig. 9).

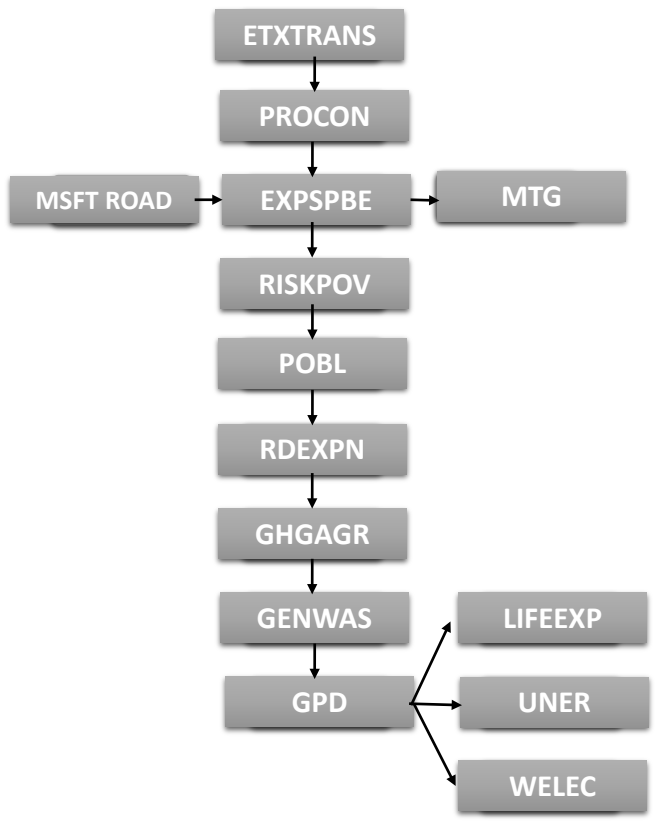

Fig. 9. EXPSPBE serial connections

Another shorter serial connection is observed in Fig. 10. There, REPRO (productivity of resources) has 2 parents on whom it depends on: SHAIMPT (participation in imports by EU member) and EGS (exports from member states to third countries). Even, it has a son, PROIND (production in the industry) which depends on REPRO too and, at the same time, PROIND has GHGTR (emissions of greenhouse gases from the transport) as a son, which depends on it.

Finally, a hierarchy was established between the variables. Therefore, importance degree of each one was defined taking into account the number of arcs connecting each one with the most important nodes in the network (RCU, capacity of liquefied natural gas regasification terminals under construction, and MSFT INW, modal distribution of cargo transport by inland waters). Therefore, it was possible to find that transport and international trade group and economy and finance group are the most important ones, because their variables are the closest to the root nodes of the network, and consequently, they are the least dependent. In other words, these two 
categories are significant in the decision to implement liquefied natural gas as fuel in Short Sea Shipping.

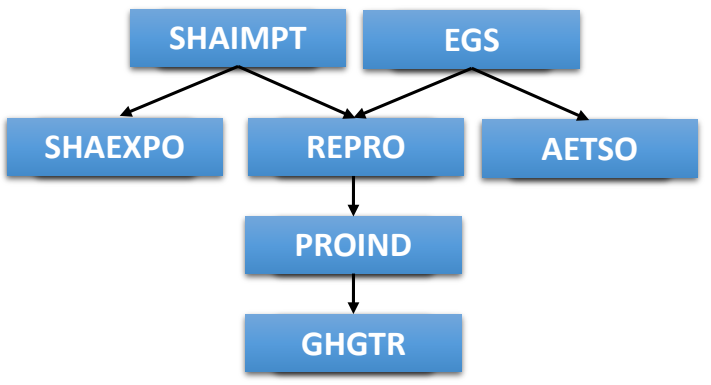

Fig. 10. REPRO serial connections

On the other hand, environment and energy group and population and social status group are the most, dependent ones and their variables are far away from the root nodes of the network.

It can be concluded that all of the considered variables have a parent, which depends on RCU (capacity of liquefied natural gas regasification terminals under construction), and $75 \%$ of them depends on MSFT INW inland waters). These two root variables are important in making-decision because both do not depend on any other variable in the network.

\section{Conclusions}

Maritime freight transport intensification has generated the need to seek more environmental friendly fuels as liquefied natural gas, which conforms one of the alternatives. Relating to this item, a research was carried out and a methodology was successfully developed using data mining techniques, in order to determine the relationship between the variables that define the use of liquefied natural gas in Short Sea Shipping in Europe.

A Bayesian network was constructed with the 35 indicators classified in 5 categories.

Main result was establishment of capacity of liquefied natural gas regasification terminals under construction and modal distribution of water cargo transportation continental as the two root nodes of the network. It means that both are the most important variables in the decision to implement liquefied natural gas as fuel in Short Sea Shipping.

Likewise, group analysis shows that the variables of transport and international trade and economy and finance are the most relevant in the decision-making process when implementing liquefied natural gas. However, variables of environment and energy group and population and social status group are the most dependent ones on the entire network, so they are more affected than the variables of the rest of categories.

\section{References}

[1] Acedo, A., Almazán, J. Pasado, Presente y futuro de las Autopistas del Mar en Europa, Revista de Obras Públicas, No. 3565, pp. 31- 38, 2015.

[2] Acid, S., De Campos, L. M., Approximations of causal networks by polytrees: An empirical study, Advances in Intelligent Computing, IPMU'94, pp. 149-158, 1995.

[3] Almazán, J. L., Palomino, M., González, N., Soler, F., y Iribarren, E. Estimation of Spanish bunkering at EU level of secas, Research Conference In Technical Disciplines, Section Transport and Logistic, pp. 136-141, 2013.

[4] Almazán-Gárate, J. L., Palomino-Monzón, M. C., González-Cancelas, N., Soler-Flores, F., Relationship between air pollution and natural gas with respect to maritime transport, Methodology based on Bayesian Networks. Global Virtual Conference, Transport and Logistics Section, 7-11 April 2014.

[5] Bengtsson, S. K., Fridell, E., Andersson, K., Fuels for short sea shipping: A comparative 
assessment with focus on environmental impact, Journal of Engineering for the Maritime Environment, Vol. 228, pp. 44-54, 2014.

[6] Brynolf, S., Andersson, K. E., Fridell, E., A comparative life cycle assessment of marine fuels, Journal of Engineering for Maritime Environment, Institution of mechanical engineers, 2011.

[7] Cánovas, B., Short Sea Shipping, una estrategia Europea, Documento de Opinión, No. 70. Instituto Español de Estudios Estratégicos, 2015.

[8] Comisión Europea, Libro Blanco, La política europea de transportes de cara al 2010: la hora de la verdad (pp. 11-53), COM (2001) 370 final, Bruselas: Commission of the European Communities.

[9] Comisión Europea, Libro Verde, Estrategia europea para una energía sostenible, competitiva y segura (pp. 3-19), COM (2006) 105 final. Bruselas: Commission of the European Communities.

[10] Cooper, G. F., Herskovitz, E., A Bayesian method for the induction of probabilistic networks from data, Machine Learning, 9(4):309-348, 1992.

[11] Friedman, N., Goldszmidt, M., Building classifiers using Bayesian networks, Proceedings of the National Conference on Artificial Intelligence, Menlo Park, Ca: AAAI Press, 1996.

[12] Gritsenko, D., Yliskylä-Peuralahti, J., Governing shipping externalities: Baltic ports in the process of SOx emission reduction, Maritime Studies, Vol. 12, No. 10, 2013.

[13] Heckerman, D., A tutorial on learning with Bayesian networks. Innovations in Bayesian networks, (pp. 33-82), Springer Berlin Heidelberg, 2008.

[14] Kegalj, I., Traven, L., Influence of Cargo flows on Sustainable Development of East Mediterranean "Motorways of the sea", Journal of Maritime \& Transportation Sciences, Vol. 53, No. 1, pp. 19-33, 2017.

[15] Laskey, K. B., Sensitivity analysis for probability assessments in Bayesian networks, In Proceedings of the Ninth Conference on Uncertainty in Artificial Intelligence, 2014.

[16] Lloyd, M., Regional action for logistical integration of shipping across Europe (realise), Work package 4, Task 4.1 multi-modal pricing and costing analyses inception report, 2003. Available in: http://www.realise-sss.org/.

[17] Niedermayer, D., An introduction to Bayesian networks and their contemporary applications, In Innovations in Bayesian Networks, Springer Berlin Heidelberg, pp. 117-130, 2008.

[18] Nižić, F., Frančić, V., Orović, J., Ships' Solutions for meeting the International requirements regarding the reduction of Air Pollution, Journal of Maritime \& Transportation Sciences, Vol. 53, No. 1, pp. 53-65, 2017.

[19] Puga, J. L., García, J. L., De la Fuente Sánchez, L., de la Fuente Solana, E. I., Las redes bayesianas como herramientas de modelado en psicología, Anales de Psicología, 23(2), 307-316, 2007.

[20] Psaraftis, H. N., Kontovas, C. A., CO Emission Statistics for the World Commercial Fleet, WMU Journal of Maritime Affairs, Vol. 8, No. 1, pp. 1-25, 2009.

[21] Psaraftis, H. N., Kontovas, C. A., Balancing the Economic and Environmental Performance of Maritime Transportation, Transportation Research Part D: Transport and Environment, Vol. 15, No. 8, pp. 458-462, 2010.

[22] REALISE, Regional Action for Logistical Integration of Shipping across Europe, The Alliance of Maritime Regional Interests in Europe (AMRIE), GTC2-2000-33032. 2002. Available in: http://www.realise-sss.org.

[23] REALISE, The Alliance of Maritime Regional Interests in Europe, (AMRIE), Final Report No. GTC2-2000-33032, Available in: http://www.realise-sss.org, 2005.

[24] RECORDIT, Actions to Promote Intermodal Transport: Final Report No. WP9, 2003, Available in: http://www.recordit.org/.

[25] Rodríguez, D., Dolado, J., Redes Bayesianas en la Ingeniería del Software, 2007. 